\title{
An Exploration of the Relationship between Transformational Leadership and Organizational Commitment: The Moderating Effect of Emotional Intelligence: Case Study in Iran
}

\author{
Majid Farahani, \\ Department of Public Administration, School of Management and Accountancy, Islamic Azad University \\ Qazvin Branch, Qazvin, Iran \\ E-mail: farahani@qiau.ac.ir \\ Marzieh Taghadosi \\ Department of Public Administration, School of Management and Accountancy, Islamic Azad University \\ Qazvin Branch, Qazvin, Iran \\ E-mail: taghadosi_ps@yahoo.com \\ Mehdi Behboudi (Corresponding Author) \\ Department of Business Management, School of Management and Accountancy, Islamic Azad University \\ Qazvin Branch, Qazvin, Iran \\ E-mail: behboudi1983@gmail.com
}

Received: May 28, 2011

Accepted: May 10, 2011

doi:10.5539/ibr.v4n4p211

\begin{abstract}
Purpose: This research aims to explore the relationship between transformational leadership and organizational commitment. In addition, we intend to study the effect of emotional intelligence, which moderates the relationship of transformational leadership and organizational commitment.
\end{abstract}

Research methodology/design: Insurance experts $(n=214)$ working in 6 branches of Social Security Organization of Qazvin province completed a measure of EI (Bar-On's self-report Emotional Intelligence Inventory), Multi Factor Questionnaire (MLQ), a measure of transformational leadership, and a questionnaire of organizational commitment.

Findings: Correlational and regression analysis revealed that there is a direct and positive relationship between transformational leadership and organizational commitment. Also results show that emotional intelligence moderates the relationship between transformational leadership and organizational commitment.

Originality/value: This paper establishes a link between transformational leadership and emotional intelligence. It, also, shows that follower's emotional intelligence moderates that relationship. One of the managerial applications of our result is that effectiveness of transformational leadership depends on follower's EI. It means that managers who have transformational leadership style are effective when their followers are high on EI.

Keywords: Transformational leadership, Organizational Commitment, Emotional Intelligence

\section{Introduction}

Modern organizations face with new challenges requiring them to adopt effective decisions in order to resolve complicated issues. Such decisions are usually adopted in the top of organization. On this level, leaders and directors enjoy power and control for influencing objectives of organization. Every organization needs effective leaders who fulfill organizational productivity by increasing follower's job satisfaction, performance and commitments. The potential consequences relating to influence and efficiency of leadership behavior will affect organizational objectives. These objectives may include: increasing morale, occupational satisfaction, organizational commitments; or decreasing absence, delays or dislocation and transfers of personnel. Hence, organizations will determine what type of leadership behavior will create the most desirable consequences. Transformational leadership style is among leadership styles on which effectiveness is emphasized by numerous researches (Sivanathan Niroshaan, Fekken G. Cynthia, 2002). 
Transformational leadership style shall be defined as: The procedure for conscious influence in individuals or groups for making continuous changes and developments in status quo and performance of organization as a whole (Koh William, Avolio Bruce J, Zhu Weichun, and Bhatia Puja, 2004).

On the other hand, organizational commitment shall be defined as: a psychological affection and devotion of personnel to their organization. (ibid)

Whereas many researchers have emphasized on the relationship between organizational commitments and occupational consequences such as absence, dislocation etc. (Avolio et al., 2004), the main question here is that whether transformational leadership style could influence organizational commitment? On the other hand, many researchers emphasize that commitment may be directed to various objectives (commitment to organization, commitment to superiors, commitment to colleagues and clients) (Koh et al., 2004).

Many researches show that characteristics of followers have effective roles on effectiveness of leadership style. Among personal variables we would imply emotional intelligence to which many attentions have been paid in management literature (Barling et al., 2000). Emotional intelligence is defined as the intelligence to applying emotions, moral and sense for conducting behaviors, thoughts, interpersonal relationships of colleagues, superiors and clients; and using time and modality of doing works for promotion of results (ibid). Therefore, the other question arising here is that whether emotional intelligence of the followers could adjust relationship between leadership styles and various forms of commitments.

\section{Research Literature \& Hypotheses}

Transformational leadership: Some researchers comment on transformational leadership in this form: transformational leaders target basic needs of their followers (such as self-glorifying in the view of Maslow) and direct them to higher levels of enthusiasm and encouragements. For certifying the said concept some studies have been conducted and the results showed that transformational leadership relates to behavioral and working intentions of individuals and organization; and the mechanisms and procedures applied by transformational leaders will impact on emotions and performance of followers (Barling et al., 2000). Transformational leadership provides a basis for long-term organizational changes that in turn it will provide necessary grounds for reaching to higher goals of organizational system. Organizational evolutions need transformational leaders.

Transformational leadership will lead to satisfaction of followers and trust to leadership and will require the employees to render effective services. In the presence of transformational leadership, attentions have been paid to other relevant issues such as improvement of such leadership and other relevant factors such as ethical progress which they themselves make the individuals ready to use such leadership (ibid).

McColl-Kennedy and Anderson (2005) further defined transformational leadership style as "guidance through individualized consideration, intellectual stimulation, inspirational motivation, and idealized influence" (Schneide $e t$ al., 2011).

Transformational leadership relates to a procedure by which passionate changes in objectives and strategic goals of organization are extended (Barling et al., 2000).

Transformational leadership is widely revealed in researches concerning leadership as a pattern in organizational psychology. Transformational leadership is capable for encouraging followers for doing over-expected works (ibid).

Organizations with transformational leadership cultures tend to be more effective, for example by being better able to adapt to change Transformational leadership is related to employees' perceptions of effectiveness, of a leader and satisfaction with a leader enhanced motivation greater effort, better job performance and greater job satisfaction, greater innovative work behavior and greater involvement with a work team (Fitzgerald et al., 2010)

\section{Dimensions of Transformational leadership}

Idealistic Influence: In leadership literature the first dimension of evolution-oriented leadership is idealistic influence or in the view of some authors it is charisma or charismatic leadership. The most important organizational studies related to charisma are conducted by House. In his concept, House comments three major characteristics of charismatic leaders as follows: having high level of self-confidence, feeling a need for having high influence, and capability for convincing followers very strongly of the fact that their beliefs are correct on ethical point of view.

Mental Encouragement: This term implies encouraging followers by leader for discovering new solutions and rethinking in order to resolve organizational problems by them. In fact, the behavior of leader makes a challenge for followers to do their efforts for fulfilling works and to rethink on those matters which might be done.

Inspiring Motivation: Increase in awareness of missions and views of organization and motivating the followers for perception of such issues and attracting their commitments toward organization are among major aspects of 
"inspiring motivation". Inspiring motivation considers the existing principles in the organization and bestirs followers within these principles.

Personal Considerations: In personal considerations point of view, the dynamic leader analyzes and follows the needs of each person through establishing a relationship with each member of group separately. Leader will stimulate each individual via creating relationships with and assigning duties to him/her considering personal differences of members of group. It is noteworthy that such leaders pay attention to the personal differences of their followers closely; and they always work along with their followers as consultants; and guide them with due consideration of characteristics of each person.

\section{Organizational Commitment}

Although multiple definitions of organizational commitment have been proposed, they each share the view that commitment is a psychological state that characterizes an employee's relationship with his or her organization and has implications for that employee continuing membership in the organization (see Meyer \& Allen, 1997). What has traditionally differed among these definitions of organizational commitment is the nature of the psychological state being described (e.g., Becker,1960; Mowday, Steers, \& Porter, 1979; Wiener, 1982). In order to acknowledge these differences, Meyer and Allen (1991) developed a three-component model of organizational commitment. The first component is affective commitment, which refers to an employee's "emotional attachment to, identification with, and involvement in an organization" (Meyer \& Allen, 1991, p. 67).The next component is continuance commitment, which refers to an employee's perceptions of the costs associated with leaving an organization. The last component is normative commitment, which refers to an employee's feelings of obligation to remain in his or her organization

The other definition of the organizational commitment is :

the relative strength of an individual's identification with and involvement in a particular

organization (Gunlu et al., 2010)

Concept of "organizational Commitment" is expressed by three different dimensions:

Affective Commitment

Normative Commitment

Continuance commitment

Affective Commitment is defined as a positive sense of identification with or involving in organization (Saroughi \& Ahmad, 1996).

Meyer and Allen (1991) stated that such characteristics as personal, structural, occupational and experimental ones are preliminary conditions of affective commitment. Normative Commitment is defined as "Commitment on the basis of a sense of duties toward organization"; which emphasizes commitment of person to organization and its management (Starvan, 1998).

Those employees who have strong affective commitment will remain in organization because they desire their conditions. Employees with strong continuance commitment will remain in organization because they need organization; and those who have strong normative commitment will remain in organization because they feel ethical responsibility for doing works.

Leadership is one of factors which is considered as influencing organizational commitment (ibid).

Barling (1996) found that employee's commitment to organization is directly depended on behaviors of their transformational leaders. According to "Massy" there is a positive relationship between transformational leadership and employee's motivation. Transformational leadership would affect employee's commitment of followers through encouraging them to think about critical issues, to apply innovative procedures, to participate in decision-making process, to create loyalty, and to fulfill their different needs.

This approach is supported by previous researches and show that Organizational Commitment is higher in those followers who are encouraged by their leaders to participate in decision-making procedures (ibid).

Shamir et al (1993), state that Transformational leaders are able to influence, both, Organizational Commitments of their followers by increasing their natural values, and reaching goals and missions of organization (Shamir et al., 1993). Hence, based on above argument the first hypothesis is posed as following:

Hypothesis 1: There is a significant relationship between Transformational leadership and Organizational Commitment.

\section{Emotional Intelligence}

Mayer and Salovey (1997) argue that emotional intelligence abilities enable individuals to recognize, understand, and manage emotions in themselves and others, and that this contributes to better relationships in the workplace. 
There are a number of authors that agree with this observation, including Cherniss (2001), who contends emotional intelligence contributes to organizational effectiveness through improved teamwork. Lopes et al., (2005) further found emotional intelligence was positively linked to interpersonal sensitivity and pro-social tendencies in teams, while Jordan and Troth (2004) found emotional intelligence positively predicted team performance. Jordan and Troth (2004) concluded this relationship was most likely due to improved working relationships within the high emotional intelligence teams. A conclusion that can be drawn from this research is that emotional intelligence contributes to enhancing workplace relationships, an essential element in effective leadership (Jordan et al., 2011).

Emotional Intelligence is accepting a combination of interpersonal affections and qualifications which will have impact on our behavior, thinking and reaction toward others (13).

This question "Whether the emotional intelligence can be learned?" has been studied by researchers. Derifouz (2006) believes: Emotional Intelligence is a non-recognitive intelligence; a thing existing beyond our skills and information. He defines: emotional intelligence is ability to percept ourselves and others, it is ability to accustoming ourselves to our environment and confronting with it (Groves, 2006).

Emotional intelligence implies the ability of recognition and identification of concepts and meanings of excitements, relationship between them, and interfering them so as to resolve issues concerning them (Mayer et al., 2000).

Emotional intelligence or non-recognitive intelligence is a social, personal and affective ability that make the person ready to adapt with environmental tensions, pressures and requirements effectively and efficiently. It includes intrapersonal and interpersonal skills of individuals (ibid).

In the last two decades the interest in Emotional intelligence has been simultaneously intense and controversial. Essentially, two distinct formulations of Emotional intelligence have emerged: an ability model and a mixed model (Bratton et al., 2011).

In recent decades Interpersonal Skills have been regarded as a basic part of effective leadership. Those leaders whose works have been so far controlling, planning and supervising the whole activities of organization, now shall motivate others, shall extend and promulgate positive beliefs and shall create sympathy and empathy between their personnel. These new requirements bring forth modern educational plans for managers to develop necessary skills in leaders and to help those organizations seeking effective leaders. Hence, emotional intelligence is one of the basic variables that are brought forth as a potential characteristic for effective leaders (Barling et al., 2000). Whereas positive organizational consequences are formed by transformational leadership, researchers suggest some predictive factors for transformational leadership behaviors.

Such factors are resulted from transformational leadership theory and are potential for increasing leadership education. One of these factors is emotional intelligence (Ashforth et al., 1995).

Golman strongly discusses that emotional intelligence is necessary for a successful leadership (Barling et al., 2000).

Some reasons state us why those persons with higher affective approaches use dynamic behaviors more:

1 - Leaders who know and are able to manage their sentiments and affections and show control and delay in decision-making for attracting satisfaction of others, could be a model for their proponents. Therefore, they would attract their trusts and respects. This issue is adaptive with requirements of desirable influence.

2 - Having stressed on sentiments of others, those leaders who have higher affective approaches could recognize expectation of their proponents; a sign of internal stimulation and motivation.

3- The main part is special attention to the needs of individuals and meeting their requirements. Those leaders who show emotional intelligence have special attention to capabilities and abilities of others which it is in turn a sign of positive management.

According to the view of Golman (1999), the concept of emotional intelligence should be paid attention in leadership development strategies. A leader should have high emotional intelligence for success (ibid).

According to Golman, high emotional intelligence is necessary for directors and leaders because they are representatives of organization in general assemblies and public meetings and they have the most interaction with the insiders and outsiders of company. They are who have morale of their personnel in hand. Leaders who have empathy with others, would be able to percept the requirements and needs of their personnel and to present a useful backup to them. The recent researches on emotional intelligence and leaderships represents that those leaders who have higher emotional intelligence show transformational leadership behaviors more (Shannon, Jones, Macaleer, William,2002). The affective dependence in work place is related to the growth of researches of transformational leadership. Emotional intelligence is a key factor of personal capabilities (ibid). Researchers state that emotional intelligence is a major and fundamental factor in leadership literature that sets effective leadership (Ashforth and Humphrey, 1995). 
It is believed that emotional intelligence of leaders would elevate productivity and efficiency in all levels of organization. Emotional intelligence of leaders plays a positive role in efficiency and quality of interactions with other persons in the organization (Kerr et al., 2005).

In his Ph.D. thesis in 2008, Pile studied the relationships of affective intelligence and critical thoughts with transformational leadership. The results show a positive relationship between emotional intelligence and transformational leadership. While there is a high relationship between emotional intelligence with transformational leadership the critical thoughts has not shown such relationship.

Meyer (2000) suggests that high levels of emotional intelligence enables leaders to control sentiments of group members and consequently to achieve proper performance (Sosik and Megerian, 1999).

Therefore, in the light of foregoing, the second hypothesis shall be developed as follows:

Hypothesis 2: Emotional intelligence moderates the relationship between transformational leadership and employees' commitment to the organization. As a result the higher the Emotional intelligence is, the weaker the relationship between transformational leadership and their employees' commitment to the organization.

\section{Research Methodology}

The study sample consisted of 214 individuals living in Qazvin, Iran. Respondents were Insurance experts working in 6 branches of Social Security Organization of Qazvin province. 214 questionnaires were distributed and 142 were completed and returned for a response rate of $67 \%$. Data was collected by convenience sampling in which participants have been selected from available populations (Catts, Fey, Zhang, \& Tomblin, 2001) About $67 \%$ of the respondents were male. The majority of the respondents (82\%) had a bachelor's degree. The respondents' work experience varied between one and 33 years. The mean of work experience of the respondents was 13 years

\section{Procedure}

All the questionnaires were distributed by key people in the organization who had easy access to the respondents. Key people were those who known fully organizations and had familiar with organizational procedures. These key people were selected by this paper's authors and were trained about the methodology of the study. They were introduced by their managers as people who could create a link between researchers and the organization and who had access to other respondents. The completed questionnaires were handed directly back to the authors by key people.

\section{Measures}

The survey instrument consisted of four independent sections. In the first section, there was a cover letter that gave respondents information about the purpose of the study. The letter also reassured participants that their participation and responses would be confidential and that their answers would only be assessed by the researcher(s). In addition to the cover letter, there were demographic questions to determine characteristics of the respondents such as their gender, age, marital status, education and how long they had worked in general and in their current workplace.

Transformational leadership was measured using the Multi Factor Questionnaire (MLQ) developed by Bass and Avolio (1997). The scale has 24 statements and a six-point Likert scale that ranges from "strongly disagree" (1) to "strongly agree". Sample statements include: "Provides reasons to change my way of thinking about problems".

Organizational commitment was measured using the 18-item Organizational Commitment Scale developed by Meyer and Allen (1991). It has three subscales: affective, continuance and normative commitment. The affective commitment subscale has six statements that assess how the participant feels about remaining with the organization for which they work at the time. An example of a statement is "I would be very happy to spend the rest of my career with this organization." The continuance commitment subscale has six items and assesses the personal and financial costs associated with leaving the organization for which the respondent presently works. It also ascertains the availability of attractive work alternatives to their present employment. A sample continuance subscale statement is "Too much in my life would be disrupted if I decided I wanted to leave my organization now." The normative commitment subscale includes six statements. The statements assess the level of obligation an individual feels to continue with the organization because it is the right thing to do. An example of a normative subscale statement is "I would feel guilty if I leave my organization". A six-point response scale was employed, ranging from "strongly disagree" (1) to "strongly agree" (6).

We used Bar-On's self-report Emotional Intelligence Inventory from which five subscales (interpersonal, intrapersonal, adaptability, stress management and mood) were generated. Each subscale transformed to a standard score and a total emotional intelligence is derived by averaging scores across the five subscales.

\section{Data Analysis}

Data analysis was conducted in two phases. First, all scales were subjected to reliability analysis. Second, regression analysis was also used to test the hypothesis. 
Insert Table 1Here

\section{Results}

\section{Reliability analysis}

Reliability analyses were conducted for emotional intelligence, transformational leadership, and organizational commitment scales. The reliability coefficients, means and standard deviations for each variable were reported in Table IV. Result show that reliability of all questionnaire were high, hence, respondents responded to questions in a consistent manner.

Testing the hypotheses

In this section, hierarchical regression analysis is used to investigate the prediction of organizational commitment on the basis of the transformational leadership and to examine if emotional intelligence moderates relationships between these variables. Also, in these analyses the respondent variables (sex, level of education, organizational status and job experience) are entered into the equation as control variables. Table $\mathrm{V}$ shows the hierarchical regression for the prediction of organizational commitment. In the first step, the respondents' demographic variables are entered as control variables. In the second step, the transformational leadership's dimensions were entered into the equation. This produced a statistically significant increase in $\mathrm{R}^{2}\left(\Delta \mathrm{R}^{2}=0.149, \rho<0.001\right)$. Inspection of the final model (M 4) shows a statistically significant negative effect for authoritarian $(\beta=0.149, \rho \propto 0.001$ ) and positive

\section{Conclusion}

The goal of this research is analysis of relationship between transformational leadership and organizational commitment with the focus on emotional intelligence. At the first stage, we reached to this fact that the obtained results are compatible with previous studies (Samir et al, 1993), (Petrides \& Farnham 2006), (Coppers and Wible 2006), and (Pile 2008).

Also we reached to a positive and significant relationship between transformational leadership and organizational commitment the regression coefficient of which stands at 0.046 . This amount shows a positive and significant relationship. Also we found that the emotional intelligence moderates the relationship of transformational leadership and organizational commitment, the quantity of which stands at 0.026 in statistical point of view representing a positive and significant relationship.

It is noteworthy that the results of this research may be different in other provinces or in other countries. This difference may be due to cultural differences of eastern and western countries. In the light of foregoing and the results obtained, it is suggested that in order to preserve stability of organization and to maintain personnel with high organizational commitment and maximum satisfaction, directors and superiors of an organization should be selected among those persons who distinguish between their thoughts and sentiments, who are seeking honorable goals, who are able to manage their energy, who are not seeking advising, ordering, criticizing and lecturing for others, who avoid drastic excitements such as anger, happiness, and/or fear and prevent the interference of such excitements in decision-making procedure; and in one word, who have high emotional intelligence. This may be achieved by testing of emotional intelligence skills and/or conducting a personality testing.

\section{References}

Starvan, Hossein. (1998). Organizational Commitment, Qazvin, The quarterly of Management in Education, $5^{\text {th }}$ period, No. 17.

Saroughi, Ahmad. (1996). Organizational Commitment and its relationship with Intention To Service Termination, the quarterly of Public Administration, No. 35.

Ashforth, B.E. and Humphrey, R.H. (1995). Emotion in the workplace: a reappraisal, Human Relationships, Vol. 48 No. 5

Avolio, Bruce, Zhu, Welichun, Koh. William, Bhatia, Puja. (2004). Transformational leadership and organizational commitment: mediating role of emotional intelligence and moderating role of structural distance, Journal of organizational behavior. DOI:10.1002/job.283, http://dx.doi.org/10.1002/job.283

Barling, J., Slater, F. and Kelloway, E.K. (2000). Transformational and emotional intelligence: an exploratory study, Organization Development Journal, Vol. 21 No. 3.

Barling, Julian- Starter, Frank. (2000). Transformational leadership and emotional intelligence: an exploratory study, Leadership \& Organization development journal, 21/3,157-161. 
Bratton,Virginia K., Dodd ,Nancy G. Brown, F.William. (2011). The impact of emotional intelligence on accuracy of self-awareness and leadership performance, Leadership \& Organization Development Journal, Vol. 32 No. 2, pp. 127-149, DOI:10.1108/0143773111112971, http://dx.doi.org/10.1108/0143773111112971

Fitzgerald, Susan, Schutte, Nicola S.(2010). Increasing transformational leadership through enhancing self-efficacy", Journal of Management Development Vol. 29 No. 5, pp. 495-505, DOI:10.1108/02621711011039240, http://dx.doi.org/10.1108/02621711011039240

Groves, K. (2006). Leader emotional expressivity, visionary leadership, leadership effectiveness, and organizational change, Leadership Organization Development Journal, Vol. 27 No. 7.

Gunlu, Ebru, Aksarayli, Mehmet, Sahin Perc, Nilufer. (2010). Job satisfaction andorganizational commitmentof hotel managers in Turkey, International Journal of Contemporary Hospitality ManagementVol. 22 No. 5, DOI:10.1108/09596111011053819, http://dx.doi.org/10.1108/09596111011053819

Jordan ,Peter, Troth ,Ashlea. (2011). Emotional intelligence and leader member exchange The relationship with employee turnover intentions and job satisfaction, Leadership \& Organization Development Journal, Vol. 32 No. 3 , pp. 260-280, DOI:10.1108/01437731111123915, http://dx.doi.org/10.1108/01437731111123915

Kerr Robert, Garvin John, Heaton Norma and Boyle Emily, (2005). Emotional intelligence and leadership effectiveness, Leadership \& Organization Development Journal Vol. 27 No. 4.

Koh William, Avolio Bruce J, Zhu Weichun, and Bhatia Puja. (2004). Transformational leadership and organizational commitment: mediating Role of emotional intelligence and moderating role of structural distance", Journal of Organizational Behavior. 25, 951-968, DOI:10.100 2/job.283, http://dx.doi.org/10.100 2/job.283

Mayer, J.D., Caruso, D.R. and Salovey, P. (2000).Emotional intelligence meets traditional standards for an intelligence, Intelligence, Vol. 27 No. 4.

Schneider ,Sherry K. George, Winnette M. (2011). Servant leadership versus transformational leadership in voluntary service organizations, Leadership \& Organization Development Journal ,Vol. 32 No. 1, 2011 pp. 60-77, DOI:10.1108/01437731111099283, http://dx.doi.org/10.1108/01437731111099283

Shannon, Jones, Macaleer, William. (2002). Emotional intelligence: how does it affect leadership?" Retrieved from: "http://www.Interscience.wiley.com, DOI:10.1002/ert.10047, http://dx.doi.org/10.1002/ert.10047

Shamir, B., House, R. J., \& Arthur, M. B. (1993). he motivational effects of charismatic leadership: a self selfconcept theory. Organizational Science, 4, 577-594.

Sivanathan Niroshaan, Fekken G. Cynthia. (2002). Emotional intelligence, moral reasoning and transformational leadership, Leadership and organization development magazine. DOI:10.1108/01437730210429061, http://dx.doi.org/10.1108/01437730210429061

Sosik J, J and Megerian L, F. (1999). Understanding leader emotional intelligence and performance, European Journal of Innovation Management, Vol. 10 No. 1, 2007, DOI:10.1108/14601060710720546, http://dx.doi.org/10.1108/14601060710720546

Table 1.

\begin{tabular}{|llll|}
\hline Reliability analysis & & & \\
\hline Scale & Mean & Standard deviance & Reliability \\
\hline Transformational leadership & 105.94 & 19.025 & 0.848 \\
Organizational commitment & 70.67 & 12.408 & 0.727 \\
Emotional intelligence & 72.43 & 145.072 & 0.866 \\
\hline
\end{tabular}

